\title{
Awareness of cervical cancer risk factors and screening methods among women attending a tertiary hospital in Lucknow, India
}

\author{
Asma Nigar* \\ Department of Obstetrics and Gynecology, Integral Institute of Medical Sciences and Research, Lucknow, Uttar
} Pradesh, India

Received: 15 October 2017

Accepted: 08 November 2017

*Correspondence:

Dr. Asma Nigar,

E-mail: drasmanigar@gmail.com

Copyright: $\odot$ the author(s), publisher and licensee Medip Academy. This is an open-access article distributed under the terms of the Creative Commons Attribution Non-Commercial License, which permits unrestricted non-commercial use, distribution, and reproduction in any medium, provided the original work is properly cited.

\begin{abstract}
Background: Cervical cancer is the second most common cancers among women worldwide after breast cancer. It is the only cancer in which early diagnosis of precancerous lesions can be done by a very simple and sensitive test that is, paps test. Knowledge of the women about cervical cancer risk factors and awareness about its screening are the key factors that may decrease the mortality and morbidity caused by cancer cervix. Most of the cases of cervical cancer in India are diagnosed very late, because of lack of awareness about risk factors and screening methods, resulting in fatal outcome. So, this study was done to assess the knowledge of risk factors for cervical cancer, and paps smear test for its screening.

Methods: This cross-sectional study was conducted among 200 women aged 18-55 years, attending Gynaecology Out-Patient Department (OPD) in a tertiary care hospital in Lucknow. Information about their knowledge of cervical cancer, awareness of its prevention and their socio demographic characters were collected by a questionnaire.

Results: Majority (47\%) of the females were in 26-35 years of age. (81.5\%) were from rural background. $88 \%$ women were not aware of cervical cancer and its risk factors. $6.5 \%$ women were aware of the paps test. $8 \%$ were aware of probability of early diagnosis. Majority (98.5\%) were not aware of vaccination as prevention for cervical cancer.

Conclusions: Present study population shows very poor knowledge about cervical cancer risk factors and is unaware of the concept of prevention. Hence extensive health education to the public is needed regarding cervical cancer and its prevention.
\end{abstract}

Keywords: Cancer cervix, Knowledge, Paps test

\section{INTRODUCTION}

Cancer cervix is the second most common cancer among women after breast cancer worldwide. According to WHO, cancer cervix comprises $12 \%$ of all cancers in women and is the leading gynaecological malignancy in the world. In contrast to developed countries, cancer cervix is a major public health problem in developing countries like India.
India alone accounts for one-quarter of the worldwide burden of cervical cancers. ${ }^{1,2}$

It is one of the leading cause of cancer related deaths, accounting for $17 \%$ of all cancer deaths among women aged between 30 and 69 years. It is estimated that cancer cervix will occur in approximately 1 in 53 Indian women during their lifetime compared with 1 in 100 women in more developed regions of the world. ${ }^{2}$ 
Cervical cancer is preventable, yet 493,100 new cases and more than 273,000 women die each year worldwide. ${ }^{1}$

Mortality due to cervical cancer can be reduced by screening with a sensitive and very simple test i.e. paps test. By using this test early detection and treatment of precancerous lesions can be done. Pap screening decreases cervical cancer incidence and mortality by at least $80 \%$. Pap smear testing is most beneficial between 21-65 years of age.

It has been seen that paps smear testing for screening in developed countries ranges from $68 \%$ to $84 \%$. While in india this figure is very different. In india utilisation of paps smear for cervical cancer is only $2.6 \%$ to $6.9 \% .^{3-6}$

By screening the women, detection of precancerous and early cancer is possible and thus morbidity and mortality can be reduced. Utilisation of screening methods usually depend upon the knowledge about cervical cancer risk factors, symptoms, its screening methods. women in India, rarely present themselves to healthcare because of lack of awareness about risk factors for cervical cancer and its screening tests, unless they face serious problems.

So, this study was undertaken to know the knowledge about cervical cancer and awareness of cervical cancer screening among the women attending OPDs of a tertiary hospital in Lucknow.

\section{METHODS}

A cross sectional study design was used to assess knowledge of cervical cancer and screening by paps test. Women were between the ages 18 years to 55 years, visiting the hospital, between March 2017 to July 2017. 200 women were selected by random sampling technique, between the age of 18-55 years. The women were explained, in detail, about the objectives of the study and the methods used and were given the choice of accepting or declining the interview. Women who accepted the interview were asked questionnaire consisting of questions on demographic characteristics, awareness regarding cervical cancer, its risk factors and screening method (paps smear). Awareness is defined as having previously heard of the term cervical cancer. Data were expressed in percentage.

\section{RESULTS}

The data presented in Table 1 shows that age range of study population was between 18 and 55 years. Maximum women (47\%) were in the age range from 2635 years. Among them majority $(81.5 \%)$ were from rural area. All of them were married.

Age at marriage was between 15-19 years in $72 \%$ females. $77 \%$ were illiterate. It is also evident that women who had more than 3 pregnancies comprised $57.5 \%$ of the study population. $74 \%$ females were not using any contraception. In this study, $88 \%$ women when asked about the cervical cancer, said that they have never heard of cervical cancer and risk factors. So, they were not asked further regarding symptoms and etiology. Only $5 \%$ women were aware of existence of precancerous stage. When they were asked about prognosis of cervical cancer, $1.5 \%$ thought that it is curable disease, $7.5 \%$ thought that it is a dangerous disease and $10 \%$ thought that it is a fatal disease (Table 2).

Table 1: Demographic characteristics of women participating in the study.

\begin{tabular}{|c|c|c|}
\hline Characteristic & $\begin{array}{l}\text { Number } \\
(n=200)\end{array}$ & Percentage \\
\hline \multicolumn{3}{|l|}{ Age (years) } \\
\hline $18-25$ & 35 & 17.5 \\
\hline $26-35$ & 94 & 47 \\
\hline $36-45$ & 53 & 26.5 \\
\hline $46-55$ & 18 & 9 \\
\hline \multicolumn{3}{|c|}{ Residence of the respondents } \\
\hline Urban & 37 & 18.5 \\
\hline Rural & 163 & 81.5 \\
\hline \multicolumn{3}{|l|}{ Education level } \\
\hline Illiterate & 154 & 77 \\
\hline Literate & 46 & 23 \\
\hline Primary & 30 & 15 \\
\hline Secondary and above & 16 & 8 \\
\hline \multicolumn{3}{|c|}{ Age at first marriage (years) } \\
\hline $15-19$ & 144 & 72 \\
\hline$>20$ & 56 & 28 \\
\hline \multicolumn{3}{|l|}{ Parity } \\
\hline Nulliparous & 11 & 5.5 \\
\hline $1-3$ & 74 & 37 \\
\hline$>3$ & 115 & 57.5 \\
\hline \multicolumn{3}{|l|}{ Use of contraception } \\
\hline None & 148 & 74 \\
\hline Hormonal & 11 & 5.5 \\
\hline $\mathrm{Cu} \mathrm{T}$ & 14 & 7 \\
\hline Barrier & 21 & 10.5 \\
\hline Tubal ligation & 6 & 3 \\
\hline
\end{tabular}

Table 2 shows that only $12 \%$ females were aware of risk factors. All women who were aware of cervical cancer thought discharge per vaginum to be a most common risk factor that may cause cancer. Other risk factors reported from the women were bleeding $(8 \%)$, poor hygiene $(6 \%)$, high parity $(6.5 \%)$, early marriage $(5.5 \%)$, infection $(9.5 \%)$, multiple partners $(3.5 \%)$.

Table 2 also shows that when asked about symptoms only $10.5 \%$ women were aware of the symptoms. Most common symptom (10.5\%), was thought to be foul smelling discharge. Other symptoms were bleeding $(10 \%)$, swelling of cervix (9\%), and weight loss (8\%).

Table 3 shows that only $8 \%$ thought that early diagnosis is possible. Among them, 6.5\% heard of paps test for early diagnosis and $3 \%$ had previously underwent paps 
test. Source of information about the test was TV and media $(4.5 \%)$, family and friends $(3.5 \%)$ and health care professional $(2.5 \%)$. $71 \%$ women were willing to undergo paps test. When asked regarding vaccination for prevention of cervical cancer, only $1.5 \%$ heard about vaccine.

Table 2: Knowledge and awareness regarding cervical cancer symptoms and risk factors.

\begin{tabular}{|lll|}
\hline Variable & $\begin{array}{c}\text { Number } \\
(\mathbf{n = 2 0 0})\end{array}$ & $\%$ \\
\hline Aware about cancer cervix & 24 & 12 \\
\hline Existence of precancerous stage & 10 & 5 \\
\hline Knowledge about cervical cancer & & \\
\hline Curable disease & 3 & 1.5 \\
\hline Dangerous disease & 15 & 7.5 \\
\hline Fatal disease & 20 & 10 \\
\hline Prognosis not good & - & \\
\hline Treatment possible & - & \\
\hline Risk factors & & \\
\hline No knowledge & 176 & 88 \\
\hline White discharge & 24 & 12 \\
\hline Bleeding per vaginum & 16 & 8 \\
\hline Poor hygiene & 12 & 6 \\
\hline High parity & 13 & 6.5 \\
\hline Multiple sex partners & 7 & 3.5 \\
\hline Early marriage & 11 & 5.5 \\
\hline Infection & 19 & 9.5 \\
\hline Symptoms & & \\
\hline Aware of symptoms & 21 & 10.5 \\
\hline Bleeding per vaginum & 20 & 10 \\
\hline Foul discharge & 21 & 10.5 \\
\hline Swelling of cervix & 18 & 9 \\
\hline Weight loss & 16 & 8 \\
\hline & & \\
\hline
\end{tabular}

Table 3: Awareness regarding screening by paps test.

\begin{tabular}{|lll|}
\hline \multicolumn{2}{|c|}{$\begin{array}{c}\text { Nariable } \\
\text { Awareness of probability of early diagnosis }\end{array}$} & \\
\hline Yes & 16 & 8 \\
\hline No & 184 & 92 \\
\hline Awareness of the test & & \\
\hline Yes & 13 & 6.5 \\
\hline No & 187 & 93.5 \\
\hline Had underwent paps test & & \\
\hline Yes & 6 & 3 \\
\hline No & 194 & 87 \\
\hline Source of knowledge & & \\
\hline Tv and media & 4 & 2 \\
\hline Family and friends & 7 & 3.5 \\
\hline Health care professionals & 2 & 1 \\
\hline Willing to undergo paps smear examination & \\
\hline Yes & 142 & 71 \\
\hline No & 58 & 29 \\
\hline Heard of vaccination & & \\
\hline Yes & 3 & 1.5 \\
\hline No & 197 & 98.5 \\
\hline
\end{tabular}

\section{DISCUSSION}

In india approximately $68 \%$ of population belong to rural background and also are at high risk of cervical malignancy because of multiple factors like early marriage, poor hygiene, multiparity, less education, low health awareness and lack of resources.

So, awareness regarding cervical cancer and its screening methods is very much essential to reduce mortality and morbidity.

This study shows that majority of the women were of 2635 year of age $(47 \%)$. Most of them were illiterate $(77 \%)$. Among all women $81.5 \%$ were from rural area. It is evident from this study that majority of the women had poor knowledge about cervical cancer risk factors $(88 \%)$. only $10.5 \%$ females were aware of symptoms. $92 \%$ women were not aware of probability of early diagnosis. Poor knowledge (84\%) about cervical cancer and its screening has been reported from a study conducted by Roy B et al on women who attended the hospitals. ${ }^{7}$ Similar level of awareness was seen in a study by Kumar $\mathrm{H}$ who included 83 women in his study and reported that majority $(81.9 \%)$ women had very poor knowledge about cervical cancer. ${ }^{8}$

A study by Awasthi $\mathrm{S}$ et al, which was done in rural population of Kerala also showed that $(89.2 \%)$ did not know any risk factor for cervical cancer. ${ }^{6}$

In contrast to the present study, a study by Dhivya et al in rural area of Tamil Nadu reported an awareness of $75.42 \%$ for cervical cancer. ${ }^{9}$

Two studies which were done on women in rural communities have also reported awareness of about $72 \%$ although only $2-6.9 \%$ ever underwent a Pap smear test. 6,10

In the present study it was observed that only $6.5 \%$ women were aware of the test and 3\% underwent paps testing which is also similar to that shown by Kumar $\mathrm{H}$. Other studies have also reported that only $2-6.9 \%$ of women got their screening done by paps test. ${ }^{6,10}$ Low awareness about paps screening in the present study seems to be mainly due to illiteracy and rural background. But there is a study in which in spite of awareness, practice of screening was only $5 \%$ which shows that although better education and occupation have significant impact on the awareness of screening but is not proportionate to the practice of screening. ${ }^{11}$ Strong motivation and counselling is required to increase screening by paps test.

This study has shown that women in our region, lack knowledge of cervical cancer and its prevention. It is a known fact that the knowledge of cervical cancer prevention is very poor in developing nations because of poor education and deficient awareness programmes. 
This is reflected in this study with higher proportion of rural population and majority of them being illiterate.

\section{CONCLUSION}

The knowledge about cervical cancer risk factors and screening test is very poor among rural Indian women. There is need for organized education programmes to create awareness about cervical cancer and cervical cancer screening among Indian women specially, involvement of health care workers, in maintaining a good rapport with rural population and adequate motivation would be crucial in implementing a perfect screening practice.

Funding: No funding sources Conflict of interest: None declared

Ethical approval: The study was approved by the Institutional Ethics Committee

\section{REFERENCES}

1. Ferlay J, Soerjomataram I, Dikshit R, Eser S, Mathers $\mathrm{C}$, Rebelo $\mathrm{M}$ et al. Cancer incidence and mortality worldwide: sources, methods and major patterns in GLOBOCAN 2012. Int J Cancer. 2015 Mar 1;136(5).

2. Institute for Health Metrics and Evaluation. the challenge ahead: progress in breast and cervical cancer. Institute of Health Metrics and Evaluation. 2011. Available at http://www.healthdata.org/policyreport/challenge-ahead-progress-and-setbacks-breastand-cervical-cancer

3. Swan J, Breen N, Coates RJ, Rimer BK, Lee NC. Progress in cancer screening practices in the United States. Results from the 2000 national health interview survey. Cancer. 2003;97:1528-40.

4. Harry TK, Felicia MS, Ngugen S. A needs assessment of barriers to cervical cancer screening in
Vietnamese American health care providers. Californian J Health Promotion. 2006;4:146-56.

5. Gakidou E, Nordhagen S, Obermeyer Z. Coverage of cervical cancer screening in 57 countries: low average levels and large inequalities. PloS Med. 2008;5:132.

6. Aswathy S, Quereshi MA, Kurian B, Leelamoni K. Cervical cancer screening: current knowledge and practice among women in a rural population of Kerala, India. Indian J Med Res. 2012;136:205-10.

7. Roy B, Tang TS. Cervical cancer screening in Kolkata, India: beliefs and predictors of cervical cancer screening among women attending a women's health clinic in Kolkata, India. J Cancer Educ. 2008;23:253-9.

8. Kumar HN, Tanya S. A study on knowledge and screening for cervical cancer among women in Mangalore city. Ann Med Health Sci Res. 2014;4(5):751-6.

9. Dhivya B, Balakrishnan PR. Cervical cancer screening: knowledge, attitude and practices in a primary health centre in rural India. J Evidence Based Med Health Care. 2015;2(31):4530-9.

10. Asthana S, Labani S. factors associated with attitudes of rural women toward cervical cancer screening. Indian J Community Med. 2013;38:246-8.

11. Siddharthar J, Rajkumar B, Deivasigamani K. knowledge, awareness and prevention of cervical cancer among Women attending a tertiary care hospital in puducherry. $\mathrm{J}$ Clin Diagn Res. 2014;8(6):OC01-3.

Cite this article as: Nigar A. Awareness of cervical cancer risk factors and screening methods among women attending a tertiary hospital in Lucknow, India. Int J Reprod Contracept Obstet Gynecol 2017;6:5592-5. 